\title{
Precise Assessment on Birth Information at the Civil Registry and Live Births Information System in Minas Gerais, Brazil
}

\author{
Cláudia Júlia Guimarães Horta 1
}

\begin{abstract}
1 Escola de Governo Professor Paulo Neves de Carvalho. Fundação João Pinheiro. Alameda das Acácias, 70. Belo Horizonte, MG, Brasil. CEP: $31275-150$. E-mail: claudia.horta@fjp.mg.gov.br
\end{abstract}

\begin{abstract}
Objective: to assess the precision on birth information at the Civil Registry and Sistema de Informações Sobre Nascidos Vivos (Sinasc) (Live Births Information System) in Minas Gerais with the purpose to analyze the most recent fecundity level and pattern on women and to assess the hypotheses on the fertility component for populational projections adopted by the Instituto Brasileiro de Geografia e Estatistica (IBGE) (Brazilian Institute of Geography and Statistics) in the 2013 review.

Methods: the estimation level of under registration at the Civil Registry and Sinasc was based on the comparison of number of births registered by these sources with the number of births obtained from an independent source, estimated by the Brass P/F technique with adaptation.

Results: in 2010, the coverage on the Civil Registry and Sinasc was $96.0 \%$ and $95.0 \%$, respectively. In the period of 2003 to 2015, both sources point to the same trend. From 2011, the total number of births was practically the same. The corrected Total Fertility Rate and The Specific Fertility Rates had a very similar level and pattern in the period of 2010 to 2015. Discrepancies in the fertility hypotheses were observed from the IBGE.

Conclusions: from 2010, the births registered in both data sources were considered as good statistical quality in Minas Gerais and the hypotheses of the fertility level and pattern in the IBGE projections need to be revised.

Key words Under registration, Fertility, Projections, Vital Statistics
\end{abstract}




\section{Introduction}

Vital statistics are important sources of information in the development of indicators, which subsidize in planning, implementation and assessment evaluation in health policies. ${ }^{1,2}$ The information on live births occupies a relevant position in the calculation of indicators such as the infant mortality rate, proportion of births with low birth weight, maternal mortality ratio, and birth and fertility rates that subsidize populational projections and reflect on health situation and family structure which are valuable information in planning and delimitating public health policies specifically for women and children.

There are two information systems in Brazil that register births: the "Estatisticas do Registro Civil" (Civil Registry Statistics) published by the Instituto Brasileiro de Geografia e Estatística (IBGE) (Brazilian Institute of Geography and Statistics) since 1974, and the Sistema de Informações sobre Nascidos Vivos (Sinasc) (Live Birth Information System) implanted by the Ministry of Health in 1990.

\footnotetext{
"The implantation of Sinasc occurred slowly and gradually in all federation units and has been implanting since 1994 in many cities a great number of registrations than it has been published by IBGE based on the data at the civil registry, besides enabling the construction of useful indicators for the planning and management on health services."
}

The system allows to obtain:

"a profile of the live births according to the variables that
are considered important from the epidemiological point
of view, and thus many of these were also registered in
the Declaração de Óbito (DO) (Death Statement),
obtaining specific coefficients on infant mortality."4

More specifically:

"[...] ]one of the main objectives of Sinasc implantation was to provide an epidemiolo-gical profile of births, according to the variables, such as: birth weight, the Apgar score, duration of gestation, type of delivery and parity. In addition, since many of this information are also in the DO - it is possible to obtain specific infant mortality coefficients which are necessary for more detailed analyzes in the area of maternal and child health."

Even though the Civil Registry is the oldest Brazilian administrative registry, has the obligation to register births and more than 25 years since the Sinasc implementation in Brazil, there are still deficiencies in the coverage of birth information, despite of the advances conquered.

The growing understanding of the public agents in various administrative spheres and the society in general on the importance of birth registration as a primary document to citizenship has driven a number of public policies on the subject. These various actions remains and other actions incorporated over the years, aiming the access for a quick public Civil Registry document. 6

Analyzing the percentage of under registration of births in Brazil, a recent study ${ }^{7}$ pointed out an improvement in the Civil Registry coverage. In this study, the analysis performed was based on the percentage of under registration of births calculated by the difference between the births registered by the Estatísticas do Registro Civil (Civil Registry Statistics) survey and the births predicted in the Projeção da População por Sexo e Idade do IBGE (IBGE) (Populational Projection by Sex and Age). Assessing the historical series in 1980, it was equivalent to $23.8 \%$, that is, the registrations made covered $76.2 \%$ of the births expected. In the following decades, the more and less variations were observed reaching more recently, a lower level. There was a continued downward trend from 2002 to 2014 , reaching $1.0 \%$ in the latter year. This study pointed out the possible factors for non-registration of births to the precariousness access for information, health services and social assistance; the distances traveled to the registry offices; and the costs to obtain the certificate.

However, it is necessary to consider the differences of under registration in the country.

"Previous analyzes of the Civil Registry Statistics survey for 2000, 2010 and 2013 show that under registered births assume distinct values in large regions in the country with the highest percentage observed in those regions least economically developed."7 In 2014, the under registration in the North and Northeast regions would be of $12.5 \%$ and $11.9 \%$, respectively, in comparison to the others there are indications that the registrations are done completely. 7

Estimates calculated in 2000 specifically in Minas Gerais indicated that about $87.0 \%$ to $90.0 \%$ of births occurred in the State were registered in the Sinasc, in other words, a under registration of $10.0 \%$ to $13.0 \% .8-10$

In this context of positive evolution, what can be said recently about the coverage of birth registration at the Civil Registry and SINASC in Minas Gerais? 
Are there any improvement? How intense is it? Is it possible to assume completeness from the information sources?

The objective of the present study is to assess the precision on birth information at the Civil Registry and Sinasc in Minas Gerais, in order to analyze the most recent fertility level and pattern in the State and the hypothesis of fertility component for the populational projections adopted by IBGE in the 2013 review.

\section{Methods}

The estimation level of under registration at the Civil Registry and Sinasc was based on the comparison of the number of births registered by these sources with the number of births obtained from an independent source.

The main source to assess the precise Civil Registry and Sinasc adopted the available data in the Censo Demográfico Brasileiro (Brazilian Demographic Census) of 2010, which allows to estimate fertility through of the $\mathrm{P} / \mathrm{F}$ technique developed by William Brass 11 (Brass P / F).

In relation to the method used, it is known that there is in the demography field a discussion about the use of the Brass $\mathrm{P} / \mathrm{F}$ method in detriment of Gompertz Relational Method, initially also proposed by Brass. Some authors affirm that Brass $\mathrm{P} / \mathrm{F}$ method is outdated and should be replaced by other parametric methods, such as the Gompertz relational, which does not assume the assumption of constant fertility in a recent period. 12 On the other hand, other authors, assessing the best method to estimate fertility by educational groups and revenue in 2000 and 2010, and concluded that the Brass $\mathrm{P} / \mathrm{F}$ method is still the best method to be employed. ${ }^{13} \mathrm{In}$ the same direction, the authors report that Brass $\mathrm{P} / \mathrm{F}$ method is still quite adequate when compared to the birth registrations, although it is required to investigate carefully the adjusted factor level before being employed. 14

Thus, given the adequacy of the Brass $\mathrm{P} / \mathrm{F}$ method on the information of the Censos Demográficos (Demographic Census), it was used as the basis of the methodology in this article. The method uses information on the retrospective (or parity) fertility and current fertility collected through censuses or surveys of women in various age groups. The parity information corresponds to the total number of children born alive until the date of the interview. Information on current fertility refers to children born alive in the 12 -month period prior to the census or survey.
Based on this information and classified by women's age in the five year groups giving the possibility to calculate two fertility measurements: retrospective fertility or average parity by age, and the age-specific fertility rates that define the current fertility pattern. The Brass fertility technique provides the mechanisms to create compatibility of the two measurements to adjust the level.

The Brass method estimates fertility by accepting as true the structure defined by a set of specific rates of current fertility and uses the average parity of young women (20-24 years old or 25-29 years old) to correct the fertility level.

The results on the Brass technique allow to obtain specific fertility rates. These rates allow to calculate the expected number of births of each analysis unit from the following expression:

$\bar{N}_{j}=\sum_{I=1}^{7} M_{i, j} * T E F_{i, j}$

Where:

$\bar{N}_{j}=$ the number of expected births in the location of $j$.

$M_{i, j}=\begin{aligned} & \text { the number of women of the age group } \mathrm{i} \text { in the } \\ & \text { location of } j \text {. }\end{aligned}$

The coverage of the Civil Registry and Sinasc was estimated by the ratio between the number of births registered by the Civil Registry and Sinasc and the number of births expected (Brass technique):

$K_{j}=\frac{N_{j}}{\bar{N}_{j}}$

Where:

$K_{n, j}=$ the coverage level of the Civil Registry or Sinasc in the location of $j$.

$N_{j}=$ the number of births registered by the Civil Registry or by Sinasc in the location of $j$.

$\bar{N}_{j}=$ the number of births expected in the location of $j$.

When $\mathrm{K}_{\mathrm{n}, \mathrm{j}}<1$ is estimated when there is an under registration, in proportional terms (in relation to the true number of births) is given by:

$S_{n, j}=1-K_{n, j}$

However, an adaptation to the Brass method was performed according to the decrease in the specific fertility rates of women between 15 and 19 years old (f1) between the 2000 and 2010 Censuses, as it will be further detailed. The decrease in these rates has an important consequence to apply the Brass $\mathrm{P} / \mathrm{F}$ technique with an underestimation of cumulative current fertility up to the female age group of 20 to 
24 years old (F2) taking a value used of P2 / F2 to correct the reported fertility level significantly underestimated. 15 Therefore, the original Brass technique from the 2010 Census data was proposed to be an adaptation that would adopt the Census error period referred in 2000 to 2010 . The results showed that the estimated curves were very close to the adjusted curves by using the Sinasc data from the Brazilian regions where this basis information already shows good quality. 15

Such adaptation is also justified by the fact that in Minas Gerais State observed a reduction in the specific fertility rate of women between 15 and 19 years old (f1) between 2000 and 2010 Censuses, ranging from 0.0587 to 0.0388 , in other words, a decrease of $33.0 \% .15$ In Brazil, a study estimated that this decrease was about $30 \% .16$ The current article will adopt the term "modified method" for the performed adaptation and "original method" for the Brass method.

For the directly calculated estimate on fertility, the Civil Registry statistics, the Sinasc information and the IBGE female population will be used.

In what referrers to the Civil Registry statistics, the registration performed in 2003 to 2015 will be used and available by IBGE. In relation to this specific information, a correction was necessary once these data are subject to some level of under registration due to the existence of late registrations related to the year of birth. Despite the mandatory in registering births, a certain number of registrations are still performed in a later period. The information on the year of birth and the registration year is allowed to incorporate those who were registered later, a given year.

For the all those who were registered later incorporated their respective birth years. In other words, for 2003 the birth registrations were added in 2004 to 2015 , for 2004 the birth registrations were added in 2005 to 2015 , and so on until 2014, when only those registered in the following year (2015) were added. Thus as time passes, there is an under registration due to those who were registered later according to the information used here.

However, it should be noted that late registries are gradually reducing their weight in the total amount of births. It is known that most of these are performed in the first three years after the birth. ${ }^{5}$ In the present article, assessing the data in Minas Gerais, it is estimated that in 2003 it represented $3.5 \%$ of those that actually occurred and registered in that year. During the years, this percentage reduced continuously reaching to $0.62 \%$ in 2012 .
The second source of information is the number of live births registered in Sinasc. The information used is available on the website of the Departamento de Informática do Sistema Único de Saúde do Brasil (DATASUS) (Informatics Department of the Brazilian Public Health Care System) of the Ministry of Health 16 in the period of 2003 to 2014. Finally, to calculate the Taxas Especificas de Fecundidade (TEF) (Specific Fertility Rates) and the Taxa de Fecundidade Total (TFT) (Total Fertility Rate) direct methods were applied as the rate denominator for the available population by IBGE of the Projeções $d a$ População das Unidades da Federação (Populational Projections of the Federation Units) by sex and age in the period of 2000-2030.17

It should be noted that such projections were released in 2000 although

"the population enumerated in the Censo Demográfico 2000 (Demographic Census), in Brazil, suffered an adjust-

ment in its structure by sex and age through a process of demographic conciliation. This procedure sought to harmonize the demographic censuses and vital registrations". 18

The same correction was performed in the populations of the Unidades da Federação (Federation Units).

The comparison of the results obtained from the direct and indirect estimations will allow to assess the coverage of the two sources on birth information in which could classify for purposes of assessing the quality of birth registration coverage, according to IBGE (2014) in three parts: 1) under registration greater than $10.0 \%$ which will be considered deficient for the direct calculation of ,demographic indicators and low coverage on citizenship; 2) under registration between $10.0 \%$ and $5.1 \%$, though these data are used for the direct calculation of demographic indicators, but without the ideal coverage in terms of registration; 3 ) with under registration up to $5.0 \%$, considering a good statistical quality, both for demographic and social purpose.

\section{Results}

The results are divided into three parts: the under registration measurement level of the Civil Registry and Sinasc, a comparison between the fertility level and structure calculated by the Civil Registry and Sinasc and the evolutional analysis of the fertility structure compared to the fertility component projections for the IBGE projections. 
The under registration level of the Civil Registry and Sinasc

The fertility level of women in Minas Gerais calculated from the original Brass technique (TFT (Total Fertility Rate) of 1.78 children per woman) is higher than the rate calculated with the application of the modified method (TFT of 1.59 children per woman). Thus, based on the references estimations generated from the modified method, the TFT calculated is overestimated and therefore, the fertility level in Minas Gerais in the five-year period 2005-2010 was lower than what has been presented until then. Having the TFT estimation calculated by the modified method as true, the results show an improvement in the enumeration of birth registrations at the Civil Registry and Sinasc. The TFT estimated in Minas Gerais in 2010 calculated directly according to the two sources of information (1.53 children per woman and 1.51 children per woman, respectively) presenting lower values compared to the TFT calculated with the modified method (1.59 children per woman) indicating the existence of under registration.

The estimates of the number of births obtained by the modified method (expected births) and the information registered in the Civil Registry and Sinasc are also very close. As shown in Figure 1, for all the age groups the number of the expected births is higher than what was observed. The only exception occurs in the age group of young women aged 15 to 19 years old, where the opposite occurs. It is probable that there was an error due to the underestimation of the fertility information of women aged 15-19 years old in the 2010 census.

The results obtained allow to calculate the under registration level of the two sources of information Comparing the total births expected in Minas Gerais in 2010 calculated by the TEF (Specific Fertility Rate) estimates of the modified method of 266,845 births with the total of the Civil Registry of 256,140 births and SINASC of 253,488 births, there is a level of under registered births of $4.0 \%$ and $5.0 \%$, respectively, resulting in coverage levels of $96.0 \%$ and $95.0 \%$. The comparison between the total births expected in Minas Gerais in 2010 calculated by the estimates of the TEF in the original method would determine a coverage of $86.2 \%$ and $85.3 \%$, these percentages are very low with the under registration of $13.8 \%$ and $14.7 \%$ for the Civil Registry and SINASC, respectively. As mentioned earlier, these percentages significantly increased in both sources of birth data. Estimates were calculated in 2000 indicating that about $87.0 \%$ to $90.0 \%$ of the births occurred were registered at Sinasc. $8-10$

However, due to the quality assessment of coverage in birth registrations using the IBGE$^{7}$ classification, the Civil Registry and Sinasc information for Minas Gerais could be considered of good quality (less than $5.0 \%$ of under registration) both for demographic and social purposes.

Another important aspect to be highlighted is the similarity between the number of births in the Civil Registry and at Sinasc according to the age groups. The curves of 2010 are practically overlapping, although the number at the Civil Registry is higher than at Sinasc in all the women's age groups. The total number of births represents a difference of only $1.0 \%$, and in terms of age group which the highest occurred for women aged 45 to 49 years old $(17.6 \%)$

Comparison between the fertility level and structure at the Civil Registry and Sinasc

Considering the results, the fertility estimate in Minas Gerais resulting from the two sources of information were compared and analyzed, especially from 2010.

In Figure 2 shows the births registrations from the two sources of information in the period from 2003 to 2015. It is evident that the births registered at the Civil Registry and at Sinasc point to the same trend when analyzing in terms of their evolution, which is the reduction in the number of births in the period of 2003 to 2009 , a certain stability until 2013 and an increase in 2014 (despite of under registration levels observed prior to 2010). Specifically in relation to the Civil Registry, in 2015, the number of births registered was very close to in 2014; however, there are some consideration to take in account for because no corrections were made in that year. Late birth registrations would occur in 2016 and so on (unavailable information yet).

Another interesting fact to highlight is that in 2003 the two data sources registered a number of different births, in which the number is higher at the Civil Registry (4.1\%), and as of 2011 both sources have become practically the same.

Taking as a reference of the estimated percentages on under registrations, the number of births of the two data sources was corrected since 2010. For the Civil Registry, a constant correction factor of 1.042 was taken in consideration between 2010 and 2015. As for Sinasc a correction factor of 1.053 was assumed in 2010 and then a linear decreased until 2014, when it would reach the same correction factor as the Civil Registry, in other words, 1.042 . 
Births estimated by the Brass original method and the modified method and birth registrations at the Civil Registry and Sinasc- Minas Gerais - 2010.

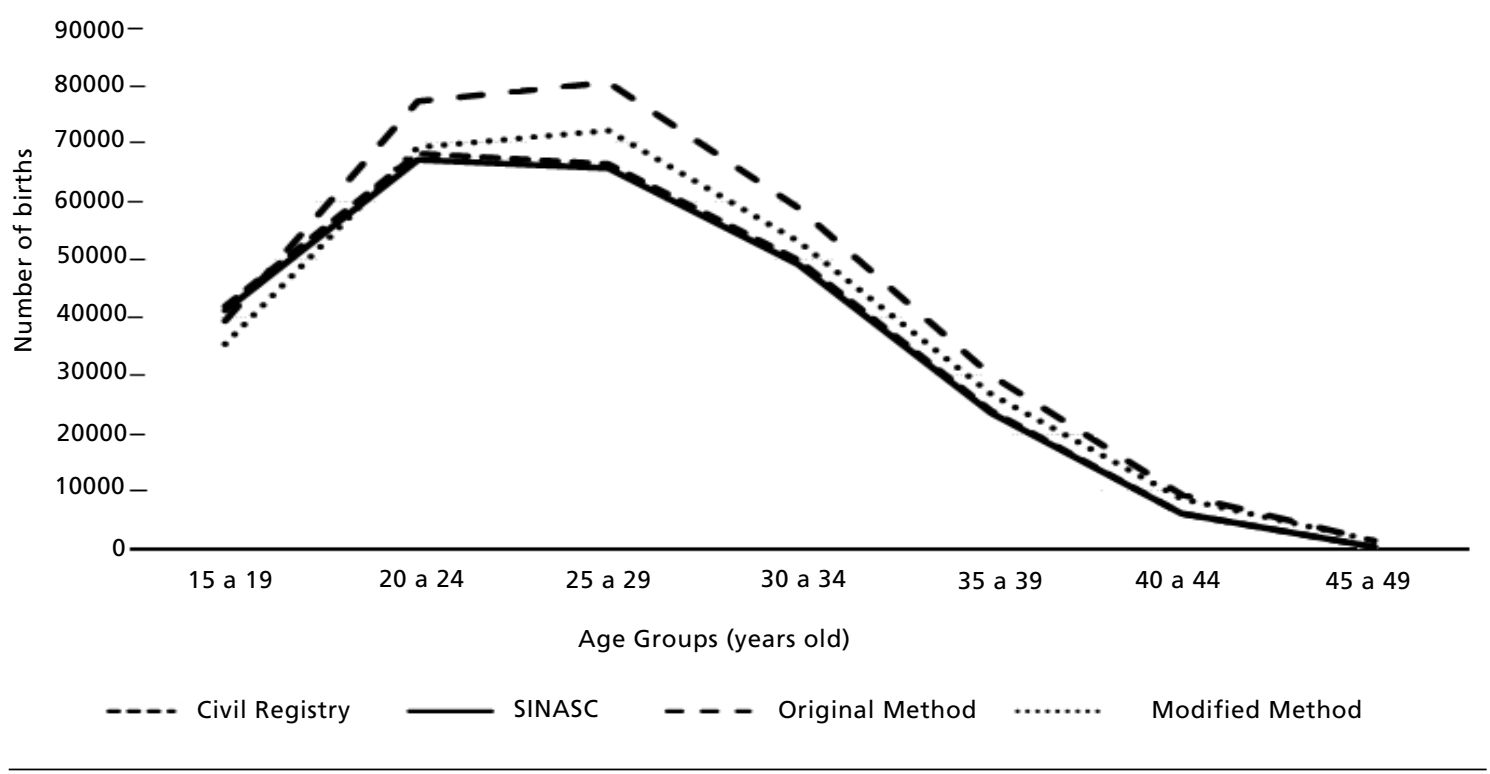

SINASC=Live Birth Information System.

Figure 2

Number of births registered at the Civil Registry and Sinasc- Minas Gerais - 2003 to 2015.

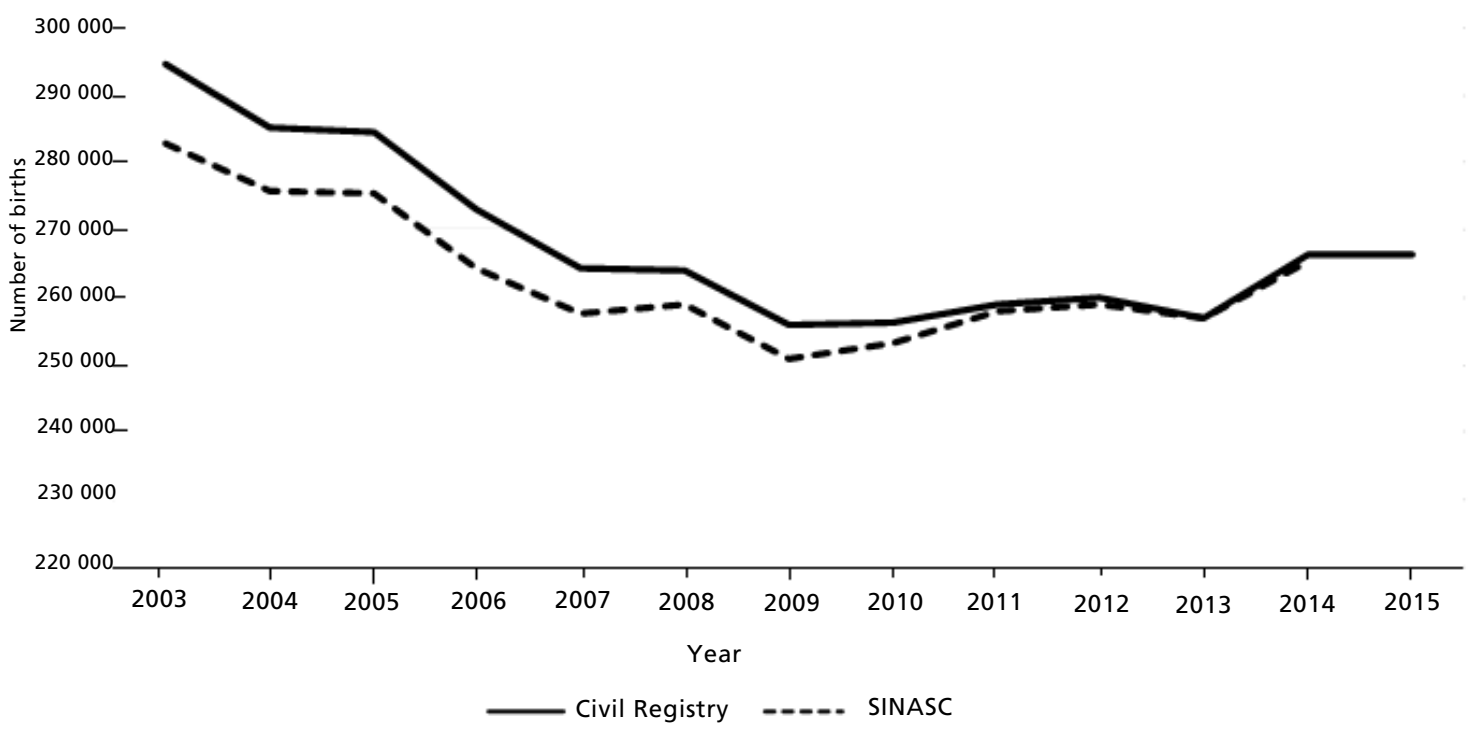

SINASC= Sistema de Informações Sobre Nascidos Vivos (Live Birth Information System). 
Table 1 presents the TEFs and the TFT for the total in Minas Gerais for the period in 2010 to 2015 using both data sources obtained and applying the correction factors. The results show that TFTs are the same during the analyzed years. The estimates show certain stability in the women's fertility level in Minas Gerais in the period: about 1.6 children per woman with a small increase in 2014 and 2015, to a close level of 1.65 children per woman. It also points out that the TEFs are also very similar and even the same in some women age groups. Therefore, it is inferred that not only the total of births but also the quantitative ones are similar according to the age groups. This reinforces the quality of the two data sources even more.

\section{Evolution of fertility in Minas Gerais and the} hypotheses of the projection

The following analysis took as a reference of the estimates generated from the Civil Registry for two reasons. First, due to the similarity between the two sources of information, and secondly, because it is possible to portray the most recent women's reproductive behavior in Minas Gerais (information for 2015).

The analysis of the fertility structure according to the age groups in 2000 , indicates an early fertility where the peak occurs in the age group between 20 to 24 years old. The fertility in this age group accounted for $25.9 \%$ of the TFT in that year (Table 2 ). In the sequence, the group of women between the ages of 25 and 29 is highlighted and also accounts for a significant percentage of TFT of $24.1 \%$; in other words, the two age groups are responsible for half of the total fertility level in Minas Gerais. Such distribution as a set, determines the average fertility age of 27.1 years old.

Over the last few years, important changes have been taking place in the women's fertility structure in Minas Gerais. The distribution analysis of the specific rates, according to the age groups in 2010 to 2015 (Table 2) shows for example, that fertility participation decreases in relation to younger women between 15 to 19 years old and with the total fertility state being more intense for the 20 to 24 year old group. For women aged 25-44 years old the opposite occurs, the weight increases in the TFT participation especially in the 35-39 age group, followed by women aged 40-44 and 30-34 years - the last two with similar elevation. These alterations resulted in an increase in the average age of fertility which increased gradually, reaching to 27.5 years in 2015 . In that same year, the age groups of 20 to 24 years old and 25 to 29 years old continued responding for half of the TFT.

Moreover, such behavior is a result of changes in the women's fertility structure in which this is characterized as late. The fertility peak is found in the 25 to 29 years old age group, a fact observed since 2014 (Table 2). In terms of TEFs, a reduction was observed in women between 20 and 24 years of age and between 45 and 49 years old, and this last group the rate is considered very low throughout the whole analyzed series. The TEFs increased in the other age groups, especially women aged 30 to 34 years old group.

According to the IBGE estimative, the TFT in Minas Gerais was 1.72 children per woman in 2010, that is a close TFR estimate obtained by the original Brass method in this article -1.78 children per woman. ${ }^{17}$ Accepting as a true estimate obtained by the modified method $(1,59)$, the IBGE TFT would be overestimated by $8.2 \%$ that year. Thus, the women's fertility level in Minas Gerais in 2010 would be lower than if it was calculated by IBGE.

There are very different trends when analyzing the corrected TFTs at the Civil Registry comparing to the TFTs of the IBGE in the period of 2010 to 2015. While the first shows some stability between 2010 and 2013 and an increase, not as significant, in 2014 and 2015, the IBGE estimates suggest a continuous decrease trend. Moreover, between 2010 and 2013, the IBGE estimates indicate a higher level of fertility than those corrected at the Civil Registry reversing this pattern in 2014 and 2015. It should be noted that the IBGE estimates of the TFTs in 2010 are based on the Censo Demográfico 2010 (Demographic Census) information in 2015 and are derived from the populational projections.

Regarding the fertility age pattern, analyzing according to the relative fertility distribution (Figure 3 ) reveals that the curves are quite similar for the women's age group between 20 to 24 years old and 30 to 39 years old. However, for other two age groups there were important differences. First, the relative participation of younger women 15 to 19 years old group which would be underestimated (by $7.0 \%$ ), while the 25 to 29 years old group would be overestimated (by $3.0 \%$ ). In the other words, the younger women fertility weight in the TFT would be higher than estimated by IBGE, while women aged 25 to 29 years old, the weight would be lower. Finally, women aged 40 to 44 years old and 45 to 49 years old also show an underestimated representation by IBGE; however it is known that the weight of these two groups in TFT is very little.

Analyzing the IBGE projections on the fertility 
Table 1

Specific Fertility Rates and Total Fertility Rate corrected by the Civil Registry and Sinasc - Minas Gerais - 2010 to 2015.

\begin{tabular}{|c|c|c|c|c|c|c|c|c|c|c|c|}
\hline \multirow{2}{*}{$\begin{array}{l}\text { Age groups } \\
\text { (In Years) }\end{array}$} & \multicolumn{6}{|c|}{ Civil Registry } & \multicolumn{5}{|c|}{ Sinasc } \\
\hline & 2010 & 2011 & 2012 & 2013 & 2014 & 2015 & 2010 & 2011 & 2012 & 2013 & 2014 \\
\hline 15 a 19 & 0.052 & 0.051 & 0.051 & 0.051 & 0.052 & 0.051 & 0.052 & 0.052 & 0.051 & 0.051 & 0.052 \\
\hline 20 a 24 & 0.082 & 0.082 & 0.080 & 0,078 & 0.079 & 0.079 & 0.082 & 0.082 & 0.080 & 0.078 & 0.078 \\
\hline 25 a 29 & 0.076 & 0.077 & 0.076 & 0,075 & 0.079 & 0.080 & 0.077 & 0.077 & 0.076 & 0.076 & 0.079 \\
\hline 30 a 34 & 0.063 & 0.064 & 0.066 & 0,066 & 0.068 & 0.068 & 0.063 & 0.065 & 0.066 & 0.066 & 0.068 \\
\hline 35 a 39 & 0.034 & 0.035 & 0.037 & 0,036 & 0.039 & 0.040 & 0.034 & 0.036 & 0.037 & 0.036 & 0.039 \\
\hline 40 a 44 & 0009 & 0.010 & 0.010 & 0.010 & 0.010 & 0.010 & 0.009 & 0.010 & 0.010 & 0.010 & 0.011 \\
\hline 45 a 49 & 0.001 & 0.001 & 0.001 & 0.001 & 0.001 & 0.001 & 0.001 & 0.001 & 0.001 & 0.001 & 0.001 \\
\hline TFT & 1.59 & 1.60 & 1.60 & 1.58 & 1.64 & 1.65 & 1.58 & 1.61 & 1.61 & 1.59 & 1.64 \\
\hline
\end{tabular}

TFT= Taxa de Fecundidade Total (Total Fertility Rate); Sinasc= Sistema de Informações Sobre Nascidos Vivos (Live Birth Information System).

Table 2

Relative distribution of the Specific Fertility Rates and the Fertility Mean Age by the Civil Registry and IBGE projections - Minas Gerais - 2010 to 2015.

\begin{tabular}{|c|c|c|c|c|c|c|c|c|c|c|c|c|}
\hline \multirow{2}{*}{$\begin{array}{l}\text { Age Groups } \\
\text { (In Years) }\end{array}$} & \multicolumn{6}{|c|}{ Civil Registry } & \multicolumn{6}{|c|}{ IBGE Projections } \\
\hline & 2010 & 2011 & 2012 & 2013 & 2014 & 2015 & 2010 & 2011 & 2012 & 2013 & 2014 & 2015 \\
\hline 15 a 19 & 16.2 & 16.1 & 16.0 & 16.2 & 15.9 & 15.4 & 15.1 & 15.0 & 15.0 & 14.9 & 14.8 & 14.8 \\
\hline 20 a 24 & 25.9 & 25.5 & 25.1 & 24.7 & 23.9 & 23.9 & 25.9 & 25.7 & 25.6 & 25.4 & 25.3 & 25.1 \\
\hline 25 a 29 & 24.1 & 23.9 & 23.7 & 23.7 & 24.2 & 24.4 & 24.9 & 24.9 & 24.8 & 24.8 & 24.8 & 24.7 \\
\hline 30 a 34 & 19.8 & 20.1 & 20.6 & 20.7 & 20.7 & 20.8 & 19.5 & 19.7 & 19.8 & 19.9 & 20.0 & 20.1 \\
\hline 35 a 39 & 10.8 & 11.1 & 11.4 & 11.4 & 11.9 & 12.2 & 10.8 & 10.9 & 11.0 & 11.2 & 11.3 & 11.3 \\
\hline 40 a 44 & 2.9 & 3.0 & 3.0 & 3.1 & 3.2 & 3.1 & 3.3 & 3.4 & 3.4 & 3.4 & 3.4 & 3.5 \\
\hline 45 a 49 & 0.2 & 0.2 & 0.2 & 0.2 & 0.2 & 0.2 & 0.4 & 0.4 & 0.4 & 0.4 & 0.4 & 0.4 \\
\hline TFT & 1.59 & 1.60 & 1.60 & 1.58 & 1.64 & 1.65 & 1.72 & 1.69 & 1.66 & 1.63 & 1.61 & 1.59 \\
\hline Idade média & 27.1 & 27.2 & 27.3 & 27.3 & 27.4 & 27.5 & 27.3 & 27.4 & 27.4 & 27.4 & 27.5 & 27.5 \\
\hline
\end{tabular}

TFT= Taxa de Fecundidade Total (Total Fertility Rate); ; IBGE= Instituto Brasileiro de Geografia e Estatistica (Brazilian Institute of Geography and Statistics). 
Figure 3

Relative distribution on Specific Fertility Rates by Civil Registry and IBGE - Minas Gerais - 2010 to 2015.
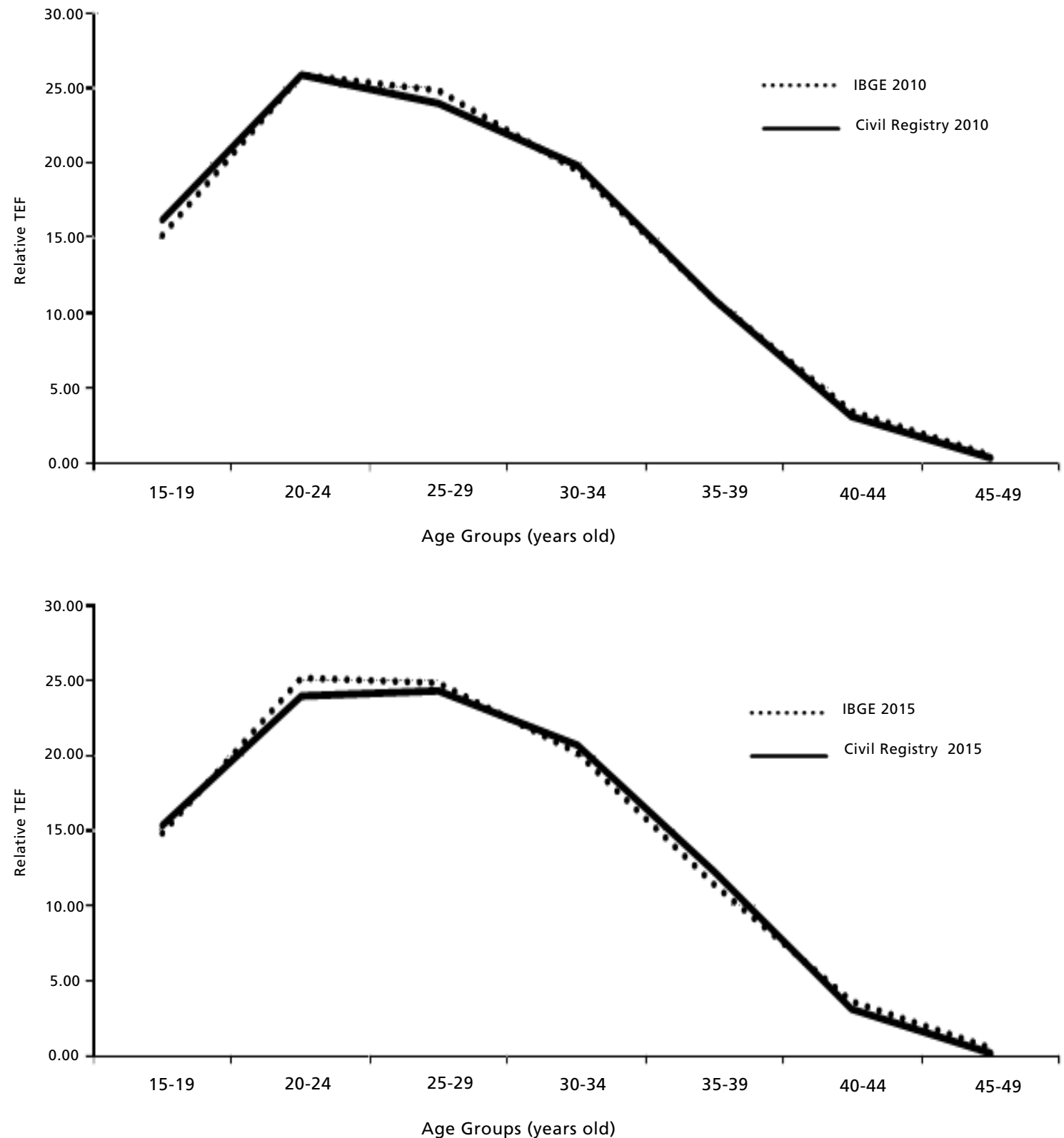

IBGE= Instituto Brasileiro de Geografia e Estatística (Brazilian Institute of Geography and Statistics); TEF= Taxa Especifica de Fecundidade (Specific Fertility Rate). 
component in 2015, it can be seen in Figure 3 that the relative fecundity of the young women aged 15 to 19 years old remains underestimated $(4.0 \%)$ compared to the Civil Registry, although a lower level to that observed in 2010. In the same condition, besides this age group, women aged 30 to 34 years old and 35 to 39 years of age with enumeration percentages under the order of $3.0 \%$ and $8.0 \%$, respectively. The other age groups were overestimated emphasizing women aged 20-24 years old with $5.0 \%$. Again, the 45-49 years old age group presents quite different representations, but they have a small participation in the TFT.

\section{Discussion}

To Improve the information systems it will be fundamental to address the challenges in health and development issues in the coming decades and to monitor progress towards the established goals. Such challenges cannot be effectively addressed without a complete system of reliable data on births and deaths. 19

The main finding in this article is the fact that the information on registered births by the Civil Registry and Sinasc in all Minas Gerais are considered of good quality, both for demographic and social purposes. As a source of information, vital statistics are extremely important in developing health indicators for policy planning, implementation and assessment. The analysis on adequacy level of vital information in Brazil demonstrated an unequivocal improvement of the situation throughout the country with some exceptions. 20 In this study, vital data are at a satisfactory level for its use in calculating development indicators and evaluating health policies. In the case of infant mortality, for example, regional differences in the quality of notifying the events (births and deaths) may lead to underestimation of rates, where this fact occurs precisely in the areas of worse socioeconomic level and greater difficulties to access the health system.

During the last years, an important point is that both women's fertility level and structure in Minas Gerais calculated by the registrations in the two sources are similar and this fact strengthens the evident information consistency. It must be reminded that such result refers to the aggregation of the State. Given to the existing regional socioeconomic inequalities, it cannot be concluded that such a finding is as well true in general. Areas with the worst health situations are those that also have a greater precariousness in the accuracy of vital statis- tics and require specific attention. 21,22

The calculated fertility estimate indicate a certain stability in women's fertility level in Minas Gerais after 2010, about 1.60 children per woman, with a small increase in 2014 and 2015 to a close level of 1.65 children per woman.

In relation to the fertility structure, there are important alterations in 2010 and 2015. Although women between the ages of 20 and 24 and 25 and 29 years old determine practically a half of the total fertility, a relative importance changed in each age group during the period. This occurred both in relation to the relative distribution and the fertility level. In the latter case, it changes from an early fertility pattern in 2010 to a late pattern in 2015 with an increase in the average age of fertility. Moreover, this finding is a result of the decrease in the fertility of women aged 20 to 24 years old and an increase in the 25 to 29 years old group. In addition, fertility increased among women aged 30 to 34 and between 35 and 39 years old, the latter is the most important. It is noteworthy that fertility decreased with young women aged 15 to 19 years old but not significantly.

The change in the women's fertility structure corroborates to the results pointed out above, regarding to the evolution of the fertility level. The women's fertility increase in the age groups of 25 to 39 years old can mean an effect of postponement of births, leading, consequently, to the increase of TFT.

Regard to the findings, the two data sources and the recent fertility behavior of women living in Minas Gerais what could be said of the estimate and hypotheses of the future fertility behavior in the IBGE projections?

The latest review on the populational projections in 2013, the IBGE incorporated important innovations, besides using more recent information on the components in demographic growth: mortality, fecundity and migration, obtained through the results of the Censo Demográfico 2010 (Demographic Census) as well as birth and death registrations. ${ }^{11} \mathrm{As}$ an innovation there are: the age structure in the starting populations was corrected, the use of the component method for the populational projections of the Unidades da Federação (Federative Units) and provided the populational projection of the five year age groups up to 90 or more years old.

The IBGE projections assume an early fecundity characteristic pattern also in 2015, while the Civil Registry shows alterations besides the highest level of fertility among women aged 30 to 34 and 35 to 39 years old, as mentioned before.

It is also important to mention the fact that the fertility level in young women aged 15 to 19 years 
old is underestimated by the IBGE, during the period of 2010 to 2015. Despite the differences have reduced over these years, the intensive decrease was lower than those considered in the projections.

Finally, the comparative analyzes of the results in this present study and the IBGE projections allow to infer that the TFT level in 2010 at a starting point of the projections are overestimated and that the assumption of trend in continuous fecundity decrease between 2010 and 2015 was not verified. In order to project the fertility level, IBGE technicians applied

"[...]a logistic function of values in the total fertility rates observed in 2000 and 2010, for each Unidades da Federação (Federative Unit) so that these values were maintained and the rates are converged to the limit located in 2030. The limit levels of total fertility rates were defined by for Unidades da Federação (Federative Units) groups that presented similar fertility behavior in the 2000s."18

Specifically in Minas Gerais, it was 1.45 children per woman by 2030 . Truly, as mentioned, it appears to have been a little increase in fertility levels after 2013.This such finding is most probably due to the effect of women postponing motherhood and would rather have children at a later age.

For the projections of the age structure of fertility, the IBGE technicians adopted as a limit the fertility pattern observed in women at six Unidades da Federação (Federative Units) that have, at least, a complete high school level: São Paulo, Rio de Janeiro, Rio Grande do Sul , Santa Catarina, Paraná, and Distrito Federal. These Brazilian States were selected by the fact that there were the highest percentage of women with this level of schooling. This choice was based on the

[...] analysis onf the behavior of the fertility structures observed for the Unidades da Federação (Federative Units) during 2000-2010, which showed an aging of fertility in all the regions. In addition, ... the improvement in educational levels would have an aging effect on the fertility structure, in which, for example, adolescent fertility, although still is at high levels, would show a decrease trend due to advances in schooling and education, as several authors have argued. 18

Therefore, it is necessary to review the fertility level and pattern used as the starting point of the IBGE populational projections in Minas Gerais State, as well as reviewing future hypotheses.

Considering the results in this present study and the different regions in Minas Gerais, in terms of the quality in birth information, it is intended to explore in further studies, the disaggregated regional information. It is expected that soon the coverage of Sinasc events will be close to $100 \%$. The authors emphasize the need for sensibility and guidance for the city managers "regarding the use of mortality and live birth data to construct appropriate indicators capable of providing adequate analysis in the health situation at a local level". 23

\section{References}

1. Laurenti R, Jorge MHPM, Lebrão ML, Gotlieb SLD Almeida MF. Estatísticas vitais: contando os nascimentos e as mortes. Rev Bras Epidemiol. 2005; 8(2): 108-10.

2. Rede Interagencial de Informação para a Saúde. Indicadores básicos para a saúde no Brasil: conceitos e aplicações. 2ed. Brasília, DF: Organização Pan-Americana da Saúde; 2008. p.349

3. Carvalho, DM. Grandes sistemas nacionais de informação em saúde. Inf Epidemiol SUS. 1997; 4: 7-46.

4. Mello-Jorge MHP, Gotlieb SLD, Oliveira H. O Sistema de informações sobre nascidos vivos: primeira avaliação dos dados brasileiros. Inf Epidemiol SUS. 1996; 2: 15-48.

5. Mello-Jorge MHP, Gotlieb SLD, Soboll MLMS, Almeida MF, Latorre MRDO. Avaliação do Sistema de Informações sobre Nascidos Vivos e o Uso de seus Dados em Epidemiologia e Estatística de Saúde. Rev Saúde Pública. 1993; 27 (Supl.): 1-48.

6. IBGE (Instituto Brasileiro de Geografia e Estatística). Estatísticas do Registro Civil. Rio de Janeiro; 2010(37): 1178. Disponível em: https://biblioteca.ibge.gov.br/visualizacao/periodicos/135/rc_2010_v37.pdf

7. IBGE (Instituto Brasileiro de Geografia e Estatística). Estatísticas do Registro Civil. Rio de Janeiro; 2014(41): 182. Disponível em: https://biblioteca.ibge.gov.br/visualizacao/periodicos/135/rc_2014_v41.pdf

8. Souza LM. Avaliação do sistema de informação sobre nascidos vivos - Sinasc, Minas Gerais e Mesorregiões, 2000. [dissertação]. Belo Horizonte: Universidade Federal de Minas Gerais; 2004

9. Horta CJG, Nogueira OJO, Perpétuo IHO, Carvalho JAM Minas Gerais e microrregiões de saúde: sub-enumeração dos nascimentos e sub-registro de óbitos infantis. In: Anais XII seminário sobre a economia mineira. Minas Gerais: Universidade Federal de Minas Gerais; 2006. Disponível em: http:/www.cedeplar.ufmg.br/seminarios/seminario_ diamantina/2006/D06A030.pdf

10. Wong LLR, Perpétuo IHO. El estudio de la salud reproductiva y los censos de 2010: la fecundidad adolescente y la mortalidad materna. Notas de Población. 2011; 92: 307335. Disponível em: http://repository.eclac.org/bitstream/ handle/11362/12886/np92307335 es.pdf?sequence=1\&isA llowed $=\mathrm{y}$ 
11. Brass W, Coale AJ, Demeny P, Heisel DF, Lorimer F, Roamniuk A, Walle EV. Demography of tropical Africa Princeton, Nova Jersey: Princeton University Press; 1968.

12. Moultrie TA, Dorrington R, Hill A, Hill K, Timaeus I, Zaba B. Tools for demographic estimation. Paris, France: International Union for the Scientific Study of Population; 2013. [acesso em 7 maio 2018]. Disponível em $<$ http://demographicestimation. iussp.org/sites/demographicestimation.iussp.org/files/TDE_2013_2ndImpression_0.p df

13. Berquó E, Cavenaghi SM. Notas sobre os diferenciais educacionais e econômicos da fecundidade no Brasil. Rev Bras Est Pop. 2014; 31(2): 471-82.

14. Cavenaghi SM, Alves JED. Qualidade das informações sobre fecundidade no Censo Demográfico de 2010. Rev Bras Est Pop. 2016; 33(1): 189-205.

15. Carvalho JAM, Gonçalves GQ, Silva LGC. Aplicação da técnica $\mathrm{P} / \mathrm{F}$ de Brass em um contexto de rápida queda da fecundidade adolescente: o caso brasileiro na primeira década do século. In: Texto para discussão, 540. Belo Horizonte, MG: Universidade Federal de Minas Gerais; 2016. Disponível em: http://www.cedeplar.ufmg.br/ pesquisas/td/TD\%20540.pdf

16. Departamento de Informática do SUS. [acesso em abr 2017]. Disponível em: http://datasus.saude.gov.br/

17. Horta CJG. Nível recente da fecundidade em Minas Gerais e Regiões de Planejamento. In: Anais do $17^{\circ}$ Seminário sobre a Economia Mineira. Belo Horizonte, MG: Universidade Federal de Minas Gerais; 2016. [acesso em 7 maio 2018]. Disponível em: http://diamantina.cedeplar. ufmg.br/2016/anais/emografia/186-307-1-RV_2016_ 10_09_00_16_25_548.pdf
18. IBGE (Instituto Brasileiro de Geografia e Estatística). Projeções da população: Brasil e unidades da federação. In: Relatórios Metodológicos, 40. Rio de Janeiro; 2013.

19. AbouZahr C, de Savigny D, Mikkelsen L, Setel PW, Lozano R, Lopez AD. Towards universal civil registration and vital statistics systems: The time is now. Lancet. 2015; 386(10001): 1407-18

20. Frias PG, Szwarcwald CL, Lira PI. Avaliação dos sistemas de informações sobre nascidos vivos e óbitos no Brasil na década de 2000. Cad Saúde Pública. 2014; 30(10): 2068280 .

21. Andrade CLT, Szwarcwald CL. Desigualdades sócio-espaciais da adequação das informações de nascimentos e óbitos do Ministério da Saúde, Brasil, 2000-2002. Cad Saúde Pública. 2007; 23(5): 1207-16.

22. Bhatia A, Ferreira LZ, Barros AJD, Victora CG. Who and where are the uncounted children? Inequalities in birth certificate coverage among children under five years in 94 countries using nationally representative household surveys. Int J Equity Health. 2017; 16(1): 148.

23. Mello-Jorge MH, Laurenti R, Gotlieb SLD. Análise da qualidade das estatísticas vitais brasileiras: a experiência de implantação do SIM e do Sinasc. Ciên Saúde Colet. 2007; 12(3): 643-54.

Received on June 06, 2017

Final version presented on June 08, 2018

Approved on August 17, 2018 